\title{
Comparison of the Metacognitive Awareness Levels between Successful and Unsuccessful Teams in the Turkish Men's Second Volleyball League
}

\author{
Dilek Sevimli \\ Department of Coaching Education, School of Physical Education and Sport, Çukurova University, Turkey
}

Copyright $\mathrm{C} 2018$ by authors, all rights reserved. Authors agree that this article remains permanently open access under the terms of the Creative Commons Attribution License 4.0 International License

\begin{abstract}
This study aimed to compare the metacognitive skill levels between successful and unsuccessful teams in the Turkish Men's Second Volleyball League in the season of 2017 - 2018. Volunteer participants consisted of 133 volleyball players from eight Clubs' teams. The metacognitive skill inventory was used for data collection. Two components of this inventory are knowledge about cognition and regulation of cognition. First includes the sub-dimensions of declarative knowledge, procedural knowledge and conditional knowledge while second consists of the sub-dimensions of planning, information management strategies, comprehension monitoring, debugging strategies (DS) and evaluation. Mann Whitney U tests were used for two group comparisons while Spearman rank order correlations were performed to analyze the relations between team success and metacognitive awareness skills. This study showed that there was no significant difference with respect to metacognitive skills between successful and unsuccessful teams' mean values except DS. The mean of DS in top three ranking team was $10.58 \%$ lower than unsuccessful teams. The difference indicates that top three rankings teams made fewer mistakes and thus have low DS while unsuccessful teams experienced more errors and they had higher DS. Execution volleyball skills without errors are critical factor for high performance.
\end{abstract}

Keywords Metacognitive Awareness Skills, Volleyball Success

\section{Introduction}

Implementation of tactical skills in sporting activities is performed possible by consciously arranging decision-making processes. The concept of metacognition is defined as the ability of the individual to regulate, control and guide the cognitive processes at the highest level [1].
Metacognitive awareness has two components [2]. These are knowledge about cognition and regulation of cognition. First component includes the sub-dimensions of declarative knowledge, procedural knowledge and conditional knowledge. Second component includes the sub-dimensions of planning, information management strategies, comprehension monitoring, debugging strategies and evaluation.

In most sporting activities, perceptual motor skills, knowledge and decision making are important components of intellectual processes. These components are at the center of sport performance with successful technical and tactical applications. This is of great importance by taking into account the sports that include open-motor skills that the volleyball player must act according to the changing game positions and situations.

Closed skill is performed automatically in a relatively unchanging environment while open skills are performed in a changing dynamic environment. While open skills are usually made against a competing athlete or team, closed skills usually cover competitors taking turns in sport environments. Allard and Starkes [3] stated that for closed skills it is critical for player to reproduce motor patterns in a consistent and reliable, defined and standardized manner. Open skills are the effective production of skill in a certain environmental condition. The cognitive demands for closed skills are generally less due to lower external monitoring and relatively constant environmental conditions. In general, the demands are essentially internal and the athletes are trying to execute and reproduce the technical skill and movement structure in a perfect way. On the other side, open skill demands the involvement of a broader range of processes due to the changing spatial-temporal requirements of the key stimuli in the environment. In this situation, the athletes must deal with both external and internal information. The performers are still trying to perfect and perform consistent movement skills but must now appropriately apply this movement pattern within an ever-changing environment. In this 
performance, they must be able to be aware of their capabilities to effectively accomplish this selection. Volleyball is known as a fast game, and efficient players need fast reactions, quick ball detection, and a good anticipation of the correct cues, and also understanding game tactics [3].

Inexperienced players often perform many errors in volleyball. They may have developed the physical skills properly but they become frustrated when they cannot perform these same skills in a game. Due to increasing their declarative knowledge, these frustrations may soon change into success. First they begin to recognize certain events and then get to know them quickly. Consequently, they understand where to move on the court, how to receive the ball, they know their responsibilities and their teammates' roles. Coach must also help players to learn how to focus on the ball better and not to be easily distracted by other players' actions. The increasing of declarative knowledge by the coach is an essential part of skill development in volleyball or any other sport. As Wall, states rich declarative base in a given sport might enhance the learning of specific skills simply because such knowledge might provide a better context for learning and problem solving [4].

Sport knowledge within the perception of motor learning; It can be divided into three information structures including declarative, procedural and strategic [5]. Declarative knowledge includes to structural information related to rules, facts and definitions. Procedural knowledge implies to how a athlete is doing something in his individual stages and strategic knowledge is information surrounding how to learn and recall in the correct context [6]. Declarative information is a prerequisite for increasing procedural knowledge in sport because during the game, an athlete must have sufficient knowledge of the declaration during the problem-solving and decision-making process [5-7]. On the other side, regulation of cognition is necessary to control actions in improving problem-solving skills and efficient performance.

During the match and training, volleyball player asks others for help when he or she doesn't understand something. So, a player changes his or her strategies when he or she fails to understand. Then it is necessary to re-evaluate assumptions when player gets confused. Finally, a player stops and goes back over new information that is not clear. Also a player stops and rereads the position or match when he or she gets confused.

Eventually, evaluating volleyball player from a knowledge based perspective may help coach understand more about how their athletes learn and the effectiveness of their own teaching. The coach may also be able to use the questionnaire as a tool to help adapt their teaching methodology to meet the different needs of all players. Self-reported evaluation of metacognitive awareness could potentially be a very valuable teaching and learning tool for coach and volleyball players during match and training. This approach makes possible to develop, implement and evaluate the self-evaluation of metacognitive awareness in volleyball players. Thus, this study aims to compare the metacognitive skill levels between first three ranking teams and unsuccessful teams in the Turkish Men's Second Volleyball League in the season of $2017-2018$.

\section{Material Method}

This descriptive study focus to compare the metacognitive awareness levels between top three ranking teams and unsuccessful teams in in Turkish Men's Second Volleyball League in the season of 2017-2018.

\section{Participants}

Data were collected from 133 voluntary volleyball players during their camps before match in Turkish Men's Second Volleyball League in the season of 2017-2018.

\section{Data Collection Instrument}

Metacognitive Awareness Inventory (MAI) was used for comparison of the metacognitive skill levels between top three ranking teams and unsuccessful teams in the Turkish men's second volleyball league This inventory was developed by Schraw and Dennison (1994) and translated into Turkish by Akın, Abacı and Çetin [7,8]. MAI is self-report inventory and has two components. These are knowledge about cognition and regulation of cognition. Knowledge about cognition as a first component of MAI has 17 questions and includes the sub-dimensions of declarative knowledge, procedural knowledge and conditional knowledge. Second component of MAI includes the sub-dimensions of planning, information management strategies, comprehension monitoring, debugging strategies and evaluation. MAI consisted of a total 52 questions, 17 questions for knowledge about cognition and 35 questions for regulation of cognition. Highest score is 260 points and lowest score is 52 points from MAI consisting of 5 point Likert type scale, ranges from 1 which is always false to 5 is always true. High scores indicate strong metacognitive awareness, while low scores indicate weak metacognitive awareness.

Lower scores indicate weak metacognitive awareness while higher scores demonstrate strong metacognitive awareness. No reverse coding was used in MAI. In the reliability study of the inventory, the Cronbach alpha coefficient was found as 0.95 , test retest reliability results was found as 0.95 , too [8].

\section{Data Analysis}

Kolmogorov-Smirnov values showed that there was no normal data distribution in this study. So, nonparametric Mann Whitney U tests were used for comparison between two groups. Spearman rank order correlations were performed to test relations between Team ranking and metacognitive skills levels. 


\section{Results}

This research aims to compare the level of metacognitive skills of male volleyball players between first three ranking teams and eliminated teams in Turkish Men's Second Volleyball League. In this context, classification of top three teams and unsuccessful teams in Turkish Men's
Second Volleyball League in the season of 2017 - 2018 was presented in Table 1. In addition, metacognitive awareness between top three teams and unsuccessful teams was shown in Table 2 while Table 3 displays the Spearman rank order correlation coefficients among success level and metacognitive variables in Turkish Men's Second Volleyball League.

Table 1. Classification of top three teams and other in Turkish Men's Second Volleyball League in the season of 2017-2018

\begin{tabular}{cccc}
\hline \multirow{2}{*}{ Name of Clubs } & \multicolumn{2}{c}{ Team Success Level } & \multirow{2}{*}{ Total } \\
\cline { 2 - 4 } & $\begin{array}{c}\text { Top Three } \\
\text { Rankings }\end{array}$ & $\begin{array}{l}\text { Others } \\
\text { Teams }\end{array}$ & 17 \\
\hline Sorgun Belediye & 17 & 0 & 16 \\
\hline Sungurlu Belediye & 16 & 0 & 16 \\
\hline St. Joseph & 16 & 18 & 18 \\
\hline Milas Belediye & 0 & 17 & 17 \\
\hline Seyhan Belediyespor & 0 & 18 & 16 \\
\hline Kayseri Melikgazi & 0 & 16 & 15 \\
\hline İnegöl Belediye & 0 & 15 & $\mathbf{1 3 3}(\mathbf{\% 1 0 0 )}$ \\
\hline Ankara Maliye & 0 & $\mathbf{8 4}(\mathbf{\% 6 3 , 1 6 )}$ & \\
\hline Total & $\mathbf{4 9 ( \% 3 6 , 8 4 )}$ & & 16 \\
\hline
\end{tabular}

*Values are the numbers of participants from each team.

Table 2. Metacognitive awareness between top three teams and others in Turkish Men's Second Volleyball League in the season of 2017 - 2018

\begin{tabular}{|c|c|c|c|c|c|c|c|}
\hline Variables & Groups & $\mathbf{N}$ & M & SD & MWU & z-value & Sig \\
\hline & Top Three & 49 & 21,39 & 2,53 & \multirow{3}{*}{2041,0} & \multirow{3}{*}{,- 080} & \multirow{3}{*}{,936 } \\
\hline \multirow[t]{2}{*}{ Age (years) } & Others & 84 & 21,38 & 2,24 & & & \\
\hline & Total & 133 & 21,38 & 2,34 & & & \\
\hline \multirow{3}{*}{$\begin{array}{l}\text { Knowledge about Cognition } \\
\text { (17-85 points) }\end{array}$} & Top Three & 49 & 48,61 & 5,29 & \multirow{3}{*}{1923,0} & \multirow{3}{*}{,- 631} & \multirow{3}{*}{, 528} \\
\hline & Others & 84 & 48,26 & 5,82 & & & \\
\hline & Total & 133 & 48,39 & 5,61 & & & \\
\hline \multirow{3}{*}{$\begin{array}{l}\text { Declarative Knowledge } \\
\text { (8-40 points) }\end{array}$} & Top Three & 49 & 23,39 & 3,07 & \multirow{3}{*}{1825,5} & \multirow{3}{*}{$-1,090$} & \multirow{3}{*}{,276 } \\
\hline & Others & 84 & 22,82 & 3,39 & & & \\
\hline & Total & 133 & 23,03 & 3,28 & & & \\
\hline \multirow{3}{*}{$\begin{array}{l}\text { Procedural Knowledge } \\
\text { (4-20 points) }\end{array}$} & Top Three & 49 & 11,57 & 2,05 & \multirow{3}{*}{1968,0} & \multirow{3}{*}{,- 425} & \multirow{3}{*}{,671 } \\
\hline & Others & 84 & 11,18 & 2,57 & & & \\
\hline & Total & 133 & 11,32 & 2,39 & & & \\
\hline \multirow{3}{*}{$\begin{array}{l}\text { Conditional Knowledge } \\
\text { (5-25 points) }\end{array}$} & Top Three & 49 & 13,65 & 2,37 & \multirow{3}{*}{1750,5} & \multirow{3}{*}{$-1,448$} & \multirow{3}{*}{, 148} \\
\hline & Others & 84 & 14,26 & 2,30 & & & \\
\hline & Total & 133 & 14,04 & 2,33 & & & \\
\hline \multirow{3}{*}{$\begin{array}{l}\text { Regulation of Cognition } \\
\text { (35-175 points) }\end{array}$} & Top Three & 49 & 98,43 & 10,15 & \multirow{3}{*}{1823,5} & \multirow{3}{*}{$-1,095$} & \multirow{3}{*}{, 274} \\
\hline & Others & 84 & 100,86 & 10,00 & & & \\
\hline & Total & 133 & 99,96 & 10,09 & & & \\
\hline \multirow{3}{*}{$\begin{array}{l}\text { Planning } \\
\text { (7-35 points) }\end{array}$} & Top Three & 49 & 19,59 & 3,30 & \multirow{3}{*}{1994,0} & \multirow{3}{*}{,- 301} & \multirow{3}{*}{, 764} \\
\hline & Others & 84 & 19,65 & 2,78 & & & \\
\hline & Total & 133 & 19,63 & 2,97 & & & \\
\hline & Top Three & 49 & 22,84 & 3,34 & & & \\
\hline Information Management Strategies & Others & 84 & 23,39 & 2,95 & 1886,5 &,- 805 & ,421 \\
\hline & Total & 133 & 23,19 & 3,10 & & & \\
\hline & Top Three & 49 & 16,80 & 2,52 & & & \\
\hline Comprehension Monitoring & Others & 84 & 17,25 & 2,85 & 1830,5 & $-1,068$ & ,285 \\
\hline & Total & 133 & 17,08 & 2,74 & & & \\
\hline & Top Three & 49 & 13,10 & 2,73 & & & \\
\hline Debugging Strategies & Others & 84 & 14,65 & 2,49 & 1393,5 & $-3,126$ &, $002 * *$ \\
\hline & Total & 133 & 14,08 & 2,68 & & & \\
\hline & Top Three & 49 & 26,10 & 3,27 & & & \\
\hline $\begin{array}{l}\text { Evaluation } \\
\text { (6-30 points) }\end{array}$ & Others & 84 & 25,90 & 3,49 & 1966,0 &,- 431 & 666 \\
\hline & Total & 133 & 25,98 & 3,40 & & & \\
\hline
\end{tabular}

**There was significant difference between two groups at $\mathrm{P}<0.01$ level. MWU=Mann Whitney $\mathrm{U}$ 
Table 3. Spearman rank order correlation coefficients among success level and metacognitive variables in Turkish Men's Second Volleyball League in the season of $2017-2018$.

\begin{tabular}{lc}
\hline Variables of Metacognitive Awareness & Team Rankings \\
\hline Knowledge about Cognition &,- 055 \\
\hline Declarative Knowledge &,- 095 \\
\hline Procedural Knowledge &,- 037 \\
\hline Conditional Knowledge &, 126 \\
\hline Regulation of Cognition &, 095 \\
\hline Planning &,- 026 \\
\hline Information Management &, 070 \\
\hline Comprehension Monitoring &, 093 \\
\hline Debugging Strategies &,$- 272^{* *}$ \\
\hline Evaluation &,- 038 \\
\hline **There was significant relationship between two variables at 0.01 \\
significant levels.
\end{tabular}

\section{Discussion}

The findings of the present investigation indicate that metacognitive processes may be fundamental to effective cognitive control during the match and training in elite volleyball players. Metacognitive processes, such as planning, monitoring, reviewing and evaluating, and metacognitive experiences were central to the adoption and initiation of cognitive strategies during playing [9]. The present study highlights the effect of metacognitive monitoring and control functions to cognitive regulation in the context of Turkish Men's Volleyball Second league.

Schraw and Dennison reported that metacognitive awareness has two components including knowledge about cognition and regulation of cognition [7]. First component consists of the sub-dimensions of declarative knowledge, procedural knowledge and conditional knowledge. Second component includes the sub-dimensions of planning, information management strategies, comprehension monitoring, debugging strategies and evaluation.

Kallio, Virta and Kallio assumed that self-evaluation is a link between the knowledge of cognition and the regulation of cognition. They greatly confirmed that planning and knowledge of conditions predict success through the learning process [9].

So, the aim of this study was to compare the metacognitive skill levels between successful and unsuccessful teams in the Turkish Men's Second Volleyball League in the season of 2017 - 2018. According to Brown, [10] declarative knowledge refers to knowledge about the self and about the personal strategies, procedural knowledge refers to knowledge about how to use these strategies, whereas conditional knowledge refers to knowledge about when and why to use strategies [10]. Regulation of cognition includes activities that are aimed at regulating or controlling learning such as planning, information management strategies, comprehension monitoring, debugging strategies and evaluation of the learning process $[11,12]$

Results of this study showed that there were no significant differences between top three ranking teams and eliminated teams with respect to all sub-dimensions except debugging strategies in Turkish Men's Volleyball Second League. Also, Spearman rank order correlations analysis showed that there was significant negative correlation between team success and metacognitive awareness skills at 0.01 significant level $\left(\mathrm{r}=-, 272^{* *}\right)$. The level of debugging strategies was increasing from success performance to unsuccessful team performance. Although top three ranking teams had higher means in knowledge about cognition of MAI first component and in the sub-dimensions of declarative knowledge, procedural knowledge and evaluation, these differences weren't significant at 0.05 levels. Also unsuccessful teams had higher means in the regulation of cognition as first component of MAI and in the sub-dimensions of conditional knowledge, planning, information management strategies, comprehension; these differences weren't significant at 0.05 levels too.

Only significant difference was observed between successful and unsuccessful teams in the variable of debugging strategies. This means that especially lower expertise volleyball player asks others for help when he or she doesn't understand something. So, this player changes his or her strategies when he or she fails to understand. Then it is necessary to re-evaluate assumptions when player gets confused. Finally, a player stops and goes back over new information that is not clear. Also a player stops and rereads the position or match when he or she gets confused.

Unsuccessful volleyball players may need to develop strategies for debugging due to the large number of errors that occur during their performance. On the other hand, successful volleyball players with demonstrating higher technical and tactical efficiency in training and matches do not need to develop strategies for debugging or to be effective in the game because, they play with little errors during the match.

The present study indicates that the average debugging strategies was only differentiated depending on success level. Unsuccessful teams had a higher mean value of debugging strategies than top three ranking teams' mean value. This can be explained by the superiority of top three ranking teams in the physical, technical and tactical performance compared to eliminate teams in Turkish Men's Second Volleyball league. This advantage does not allow them to develop their skills for debugging strategies. The successful performances of top three teams do not require consciously detecting, selecting and correcting errors during the game. Clearly, elite players' skill levels are at the autonomous phase. In this final stage of learning, skill has become almost automatic or habitual [13]. Players at this stage do not think consciously through what they are 
doing while performing the skill because they can perform it without conscious thought $[13,14]$. MacIntyre, Igou, Campbell, Moran and Matthews claimed that expertise in any field makes possible metacognitive inference. They also suggested that expertise itself may be composed of metacognitive inference among a variety of non-metacognitive processes, including working memory and motivation [15].

Efficient, extensive and well organized procedural knowledge base is developed by participation of extensive quality practice. A skilled person performing a large number of automatized skills will have to use deliberate attentional control much less often and so will execute actions more readily and efficiently than a novice. Therefore, experts are able to handle a wider variety of challenges with more proficiency than novices [16].

It is not possible to explain expert sports performance with the relation of automaticity and procedural information because declarative knowledge and metacognitive skills can also play a role in the acquisition of expertise $[17,18]$. It should be remembered that while procedural knowledge is inherently linked to optimum sport performance, declarative knowledge may play both negative [19] and positive role [20-22].

After a lot of practice at the end of the learning process, there is a striking change in athletic behavior. What was controlled and slow at an earlier stage then becomes more automatic, fluent, and fast. This is accepted as a higher level of proficiency expertise. The information processing at this expert stage is usually referred to as automatic processing [23]. There is qualitatively difference between automatic information processing and controlled processing. Contrary to controlled processing, it is fast, not attention demanding, parallel in nature, and not "volitional" in that processing is often unavoidable [24]. It is clear that number of errors decrease as performance increases. Elite athletes with fewer errors will not need the ability to debugging. Increasing metacognitive awareness may enhance training and match performance and better prepare volleyball players for developing their technical and tactical skills.

Further research is required to test the relationship between volleyball success and metacognitive awareness skills in male and female volleyball in different leagues. In sports branches requiring the intense decision making abilities the effect of metacognitive awareness education should be investigated on athlete's technical and tactical skills in martial arts, soccer, volleyball, hockey, wrestling and boxing. This study should be repeated on a larger scale and may confirm that raising metacognitive awareness levels among volleyball players is desirable.

\section{REFERENCES}

[1] Flavell, J.H. (1979). Metacognition and cognitive monitoring: A new area of cognitive-developmental inquiry. American Psychologist, 34, pp. 906-911.

[2] Schraw, G., Moshman, D. (1995). Metacognitive theories, educational psychology Review, 7, pp. 351-373.

[3] Allard, F.J. Starkes, L. (1991). Motor skill experts in sports, dance and other domains. In Ericsson \& Smith (Eds), Toward a general theory of expertise. Prospects and limits Cambridge University Press, New York,

[4] Wall, A.E. (1986). A knowledge based approach to motor skill acquisition. In M.G Wade, H.T.A. Whiting (Eds), Motor development in children. Aspects of coordination and control, Dordrecht Martinus Nyhoff Publishers,

[5] Blomqvist, M.P., Luhtanen, L., Laakso, L. (2001). Comparison of two types of instruction in badminton. European Journal of Physical Education, 6 (2): pp.139-155.

[6] Thomas, K., Thomas, J. (1994), Developing expertise in sport: the relation of knowledge and performance. International Journal of Sports Psychology, 25 (3): pp.295-312.

[7] Schraw, G., Dennison, R. (1994). Assessing metacognitive awareness. Contemporary Educational Psychology, 19, pp.460-470.

[8] Akın, A., Abacı, R., Çetin, B. (2007). The validity and reliability study of the Turkish version of the metacognitive awareness inventory. Educational Science: Theory \& Practice, 7(2), pp. 655- 680.

[9] Kallio, H., Virta, K., Kallio, M. (2018). Modeling the components of metacognitive awareness. International Journal of Educational Psychology, 7(2), 94-122.

[10] Brown, A.L. (1987). Metacognition, executive control, self-regulation, and other more mysterious mechanisms. In F.E., Weinert, R.H., Kluwe (Ed.), Metacognition, motivation and understanding Hillsdale, NJ: Lawrence Erlbaum,

[11] Artz, A.F., Thomas, E.A. (1992). Development of a cognitive-metacognitive framework for protocol analysis of mathematical problem solving in small groups, cognition and instruction, 9:2, pp.137-175

[12] Baker, L. (1989). Metacognition, comprehension monitoring, and the adult reader. Educ. Psychol. Rev., 1, pp. 3-38.

[13] Magill, RA. (2004). Motor learning: Concepts and applications (7th ed.). Boston: McGraw-Hill.

[14] Moe, VF. (2004). How to Understand Skill Acquisition in Sport. Bulletin of Science, Technology \& Society, (2004), 24, 3, pp: 213-224.

[15] MacIntyre, TE., Igou, E.R., Campbell, M.J., Moran, AP., Matthews, J. (2014). Metacognition and action: a new pathway to understanding social and cognitive aspects of expertise in sport. Front. Psychol5:1155, pp: 1-12 
[16] Norman, D.A. Shallice, T. (1980). Attention to action willed and automatic control of behavior (Tech Rep) San Diego University of California, Center for Human Information Processing.

[17] Stanley, J. Krakauer, J.W. (2013). Motor skill depends on knowledge of facts. Front. Hum. Neurosci., 7:503 pp:1-11.

[18] Toner, J. (2013). Knowledge of facts mediate "continuous improvement" in elite sport: a comment on Stanley and Krakauer, Front. Hum. Neurosci., (2014), 8:142; pp:1-2

[19] Beilock, S.L., Carr. T.H. (2001). On the fragility of skilled performance: what govern schoking under pressure? J. Exp.Psychol.Gen.,130, pp:701-725.

[20] Carson, H.J., Collins, D. (2011). Refining and regaining skills in fixation/diversification stage performers: the five-A model. Int. Rev. Sport Exerc. Psychol., 4, pp:146-167.

[21] MacIntyre, T., Moran, A., Guillot, A., Collet, C. (2013). An emerging paradigm: a strength-based approach to exploring mental imagery. Front. Hum. Neurosci1, 7,104, pp:1-12

[22] Brick, N., MacIntyre T., Campbell, M. (2014). Attentional focus in endurance activity: new paradigms and future directions. Int. Rev. Sport. Exerc. Psychol,. 7, pp:106 -134.

[23] Shiffrin, R.M., Schneider, W. (1977). Controlled and automatic human information processing: II. Perceptual learning, automatic attending, and a general theory. Psychological Review, 84, 2, pp:127-190.

[24] Schmidt, R.A., Lee, T.D. (1999). Motor control and learning: A behavioral emphasis (3rd ed.). Champaign, IL: Human Kinetics. 